\title{
SPONTANEOUS SUBCAPSULAR SPLENIC HAEMATOMA IN ACUTE MALARIA
}

\author{
D. N. Croft, B.M., M.R.C.P.* \\ Late Captain, R.A.M.C. \\ J. L. Dawson, M.B., F.R.C.S.† \\ Late Captain, R.A.M.C.
}

From the British Military Hospital, Tripoli, Libya

SPONTANEOUS subcapsular splenic hæmatoma occurring during an attack of acute malaria is not described as a clinical entity in standard textbooks of tropical medicine. Andrew (1945) suggested that it occurred in one in 600 cases of naturally acquired malaria. Read and others (1946) described a similar condition in five of 300 cases of therapeutic malaria. The following case is presented, as it is felt that this complication of acute malaria should be better known.

\section{Case Report}

Trooper E., aged 29 years, was admitted to the British Military Hospital, Tripoli, on November 18 , 1959, with a history of intermittent fever, headache, muscle pains and malaise for five weeks. The tip of the spleen was palpable. Plasmodium vivax was found in blood smears. This was his first proven attack of malaria, although he probably contracted malaria while serving in Malaya from 1956-58. He maintained he took paludrine regularly during that time.

Thirty-six hours after starting anti-malarial treatment he developed acute pain in the left hypcchondrium while lying in bed. On examination there was tenderness in the left hypochondrium with guarding. The pain gradually subsided and within a week he had no complaints. It was then possible to feel a mass under the left costal margin. The mass had a rounded edge, no notch and was larger than the spleen felt on admission. It was tender and moved on respiration. It was considered to be either a peri-splenic or a subcapsular hæmatoma. The course of antimalarial treatment given was chloroquine diphosphate (base) $900 \mathrm{mg}$. on the first day, $300 \mathrm{mg}$. daily for three days and then primaquine diphosphate (base) $15 \mathrm{mg}$. daily for two weeks. His response to this treatment was satisfactory.

Four weeks later, while stooping, he developed severe pain in the left hypochondrium. It passed off after resting but returned about one hour later and became progressively worse, spreading across the upper abdomen. He also complained of pain in the left shoulder.

On examination his temperature was $100.6^{\circ} \mathrm{F}$., pulse 80 and blood pressure 140/90. He had guarding and rebound tenderness in the left hypochondrium. He had no shifting dullness and the bowel sounds were S.E.I.

- Present address St. Thomas's Hospital, London, †Present address St. James's Hospital, Balham, London, S.W.12. normal. He was kept under close observation; after three hours the pulse had risen to 95 and the abdominal signs had spread across the whole of the upper abdomen. A provisional diagnosis of ruptured spleen was made, and it was decided to operate.

Operation. Under general anæsthesia the abdomen was opened through a left paramedian incision. The left hypochondrium was occupied by a large mass which was adherent to the anterior abdominal wall, left lobe of the liver, omentum, under-surface of the diaphragm and the left lateral abdominal wall. The mass was mobilized and found to be a spleen surrounded by a large subcapsular hæmatoma. There was no free blood in the peritoneal cavity. Splenectomy was carried out. The region of the tail of the pancreas was drained through a stab wound in the left flank. The patient was given two pints of blood, the first being commenced during the operation. He made an uneventful recovery. After his recovery he volunteered that he was free of a dull ache in the left hypochondrium for the first time since the initial episode of pain.

The specimen (Fig. I) measured overall $16 \mathrm{~cm}$. long by $12-13 \frac{1}{2} \mathrm{~cm}$. wide, and weighed $485 \mathrm{~g}$. The capsule was thickened and was lifted away from the splenic pulp, except at the hilum, by a hæmatoma which was 1.3-2 cm. thick. The spleen itself was not much enlarged, being $12.7 \mathrm{~cm}$. long by $3.8 \mathrm{~cm}$. maximum thickness from hilum to peritoneal surface. Histology showed the capsule to be infiltrated by chronic inflammatory cells. There was a marked reactive hyperplasia in the Malpighian follicles, and extreme proliferation of the sinusoidal and pulp reticulum cells, some of which contained pigment. There was a chronic inflammatory cellular infiltration with eosinophils.

\section{Discussion}

The pathology of the spleen in acute malaria is well described by Lubitz (1949). In a review of 64 cases he concluded that 'subcapsular splenic hæmorrhages in acute malaria are thus a common occurrence in the pathologic state of the spleen in acute malaria'.

Andrew (1945) reported ro cases of severe left upper quadrant pain related to an acute attack of malaria. He postulated on clinical grounds that the pain in these cases was due to subcapsular splenic hæmatoma. Half of these cases were suffering from a primary attack of malaria and three others had had only one previous attack. His excellent descrip- 


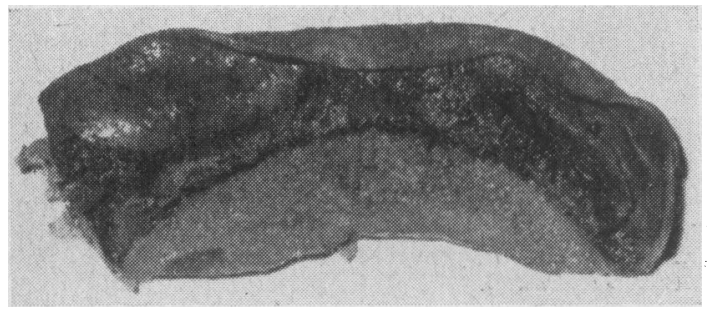

FIG. 1.-Specimen cut across to show splenic pulp; subcapsular hæmatoma and thickened capsule.

tion of this syndrome is given in full: 'The syndrome is characterized by the dramatically sudden onset of severe pain in the left upper quadrant of the abdomen, made worse by breathing, and often referred to the tip of the left shoulder. Tenderness is present in the left hypochondrium. There may be rigidity of the upper part of the abdomen, and the pain, which is constant, lasts for a few days or even many weeks. This occurrence is usually closely related to an overt attack of vivax malaria, coming on soon after the onset of fever, but in some cases days, or even many weeks later. It is entirely unrelated to trauma. More than one attack may occur and complications may develop at the base of the left lung'. None of his cases was submitted to operation. One case was followed up five months later. He complained of some aching in the left hypochondrium after severe exercise. The spleen was still enlarged and tender.

Read and others (1946), in a review of 300 cases of neuro-syphilis treated with malaria, encountered five cases of spontaneous onset of severe, lancinating pain in the left hypochondrium, which began suddenly and required the patient to lie rigidly in bed. The respiratory movements were limited by pain. The spleen enlarged from two to four fingers below the costal margin in all cases. In one case the hæmoglobin fell to $42 \%(6.5 \mathrm{~g}$.) and in another. the blood pressure fell to $80 / 40 \mathrm{~mm}$. $\mathrm{Hg}$ for 24 hours None of the patients required surgery and no follow up is mentioned.

In our case the initial attack of pain which occurred during the treatment of the febrile illness corresponds to the description given by Andrew (1945). The second attack four weeks later was more severe and progression of the abdominal signs with a rising pulse rate led to the decision t $\overline{\overline{0}}$. operate. The operative findings in our patien appear to confirm Andrew's hypothesis that the cause of pain in his cases was due to a subcapsulam hæmatoma.

A case reported by Lubitz (1949) is of interest. The patient presented with abdominal pain during an attack of malaria. The pain persisted and 9 splenectomy was performed, as it was thought the spleen might have ruptured. Examination of the spleen revealed a subcapsular hæmatoma only $5 \mathrm{~mm}$ w in diameter. It would seem from this case that even a very small subcapsular bleed can cause significant abdominal symptoms and signs.

Rapid progression of intra-splenic bleeding matu give rise to the better recognized condition of spontaneous splenic rupture (Covell, 1955). Thi usually presents during the acute phase of malaria with severe abdominal pain and evidence of intract peritoneal bleeding. Sometimes, however, the colo lapse may present without abdominal symptoms or signs (De Sarum and Townsend, 1943; Covelf 1955).

\section{Summary}

(I) A case of spontaneous subcapsular hæmatom of the spleen, related to an acute attack of malaria, is described.

(2) Attention is drawn to a syndrome, describe by Andrew (1945), of spontaneous, severe abdomina pain related to the acute phase of malaria.

(3) Operative findings in the case presente $\vec{\Phi}$ would appear to confirm Andrew's hypothesis that the cause of this syndrome is a subcapsular hæma toma of the spleen.

\section{REFERENCES}

ANDrew, R. (1945): A Syndrome in Vivax Malaria Probably Due to Spontaneous Subcapsular Hæmorrhage of the् Spleen, Med. F. Aust., 2, 460.

Covell, Sir Gordon (1955): Spontaneous Rupture of the Spleen, Trop. Dis. Bull., 52, 705.

De SARum, G. S. W., and Townsend, R. F. (1943): Spontaneous Rupture of the Spleen in Malignant Tertian Malaria? Lancet, i, 504 .

Hershey, F. B., and Lubitz, J. M. (1948): Spontaneous Rupture of the Malarial Spleen. Case report and analysis of 64 reported cases, Ann. Surg., 127, 40.

Lubitz, J. M. (1949): Pathology of the Ruptured Spleen in Acute Vivax Malaria, Blood, 4, 1168.

Read, H. S., Kaplan, L. I., Becker, F. T., and Boyd, M. F. (1946): An Analysis of Complications Encountered During Therapeutic Malaria, Ann. intern. Med., 24, 444. 